\title{
Cyclodextrin Hydrogels: Rapid Removal of Aromatic Micropollutants and Adsorption Mechanism
}

Zhenyu Yuan ${ }^{a}$, Huiqing Liu ${ }^{a}$, Hongxiang Wu ${ }^{a}$, Yiming Wang ${ }^{b}$, Qian Liu ${ }^{b}$, Yu Wang ${ }^{a}$, Stephen F. Lincolnc, Xuhong Guo ${ }^{a, d}$, Jie Wang ${ }^{a *}$

aState Key Laboratory of Chemical Engineering, East China University of Science and Technology, 200237 Shanghai, P.R. China

${ }^{\mathbf{b}}$ Department of Chemical Engineering, Delft University of Technology, $2629 \mathrm{HZ}$ Delft, The Netherlands

'School of Physical Sciences, University of Adelaide, Adelaide, SA 5005, Australia ${ }^{\mathrm{d} E n g i n e e r i n g ~ R e s e a r c h ~ C e n t e r ~ o f ~ M a t e r i a l s ~ C h e m i c a l ~ E n g i n e e r i n g ~ o f ~ X i n j i a n g ~}$ Bingtuan, Shihezi University, 832000 Xinjiang, P.R. China

*To whom correspondence should be addressed. E-mail: jiewang2010@ecust.edu.cn (Jie Wang) 


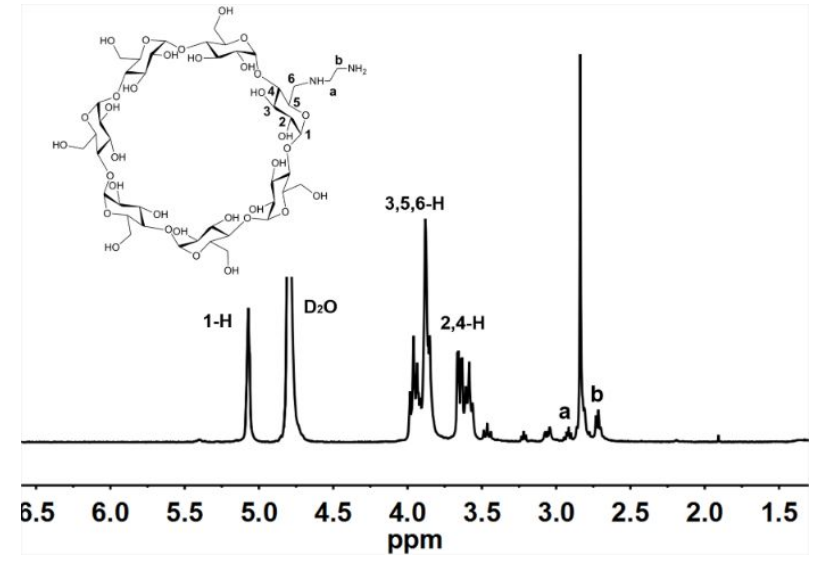

Figure S1. ${ }^{1} \mathrm{H}$ NMR spectrum of $\beta$-CD-en.

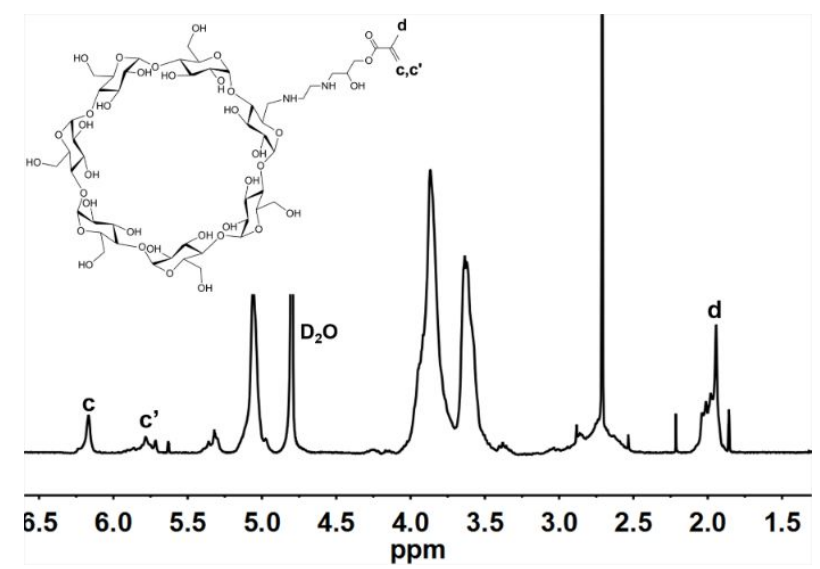

Figure S2. ${ }^{1} \mathrm{H}$ NMR spectrum of $\beta$-CD-MA.

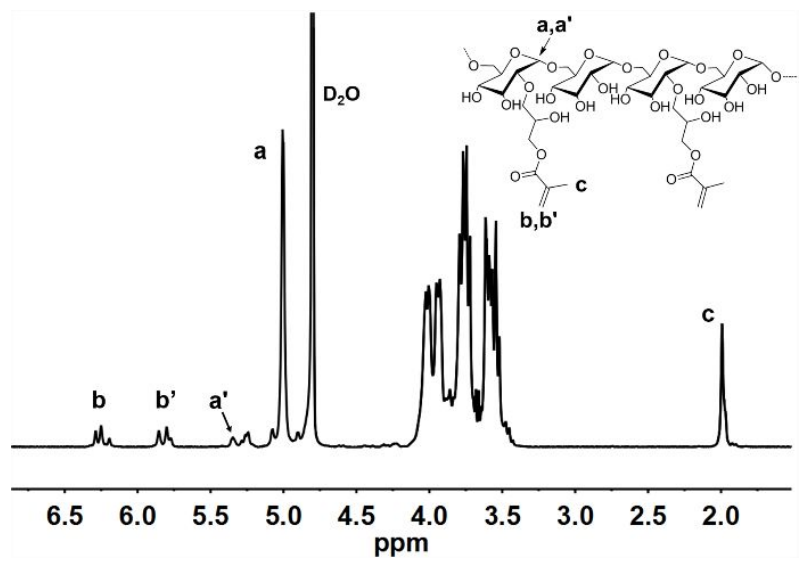

Figure S3. ${ }^{1} \mathrm{H}$ NMR (400 MHz) spectrum of Dex-MA. 
Table S1. Elemental analysis data for $\beta-C D-e n$, Dex-MA and Dex-PAA-CD.

\begin{tabular}{cccc}
\hline Sample & \multicolumn{3}{c}{ Element content (wt \%) } \\
\cline { 2 - 4 } & $\mathrm{N}$ & $\mathrm{C}$ & $\mathrm{H}$ \\
\hline$\beta$-CD-en & 2.53 & 41.55 & 6.81 \\
$\beta$-CD-MA & 2.17 & 42.68 & 6.86 \\
Dextran-MA & 0 & 39.93 & 6.76 \\
Dex-AA-CD & 0.56 & 37.50 & 5.87 \\
\hline
\end{tabular}
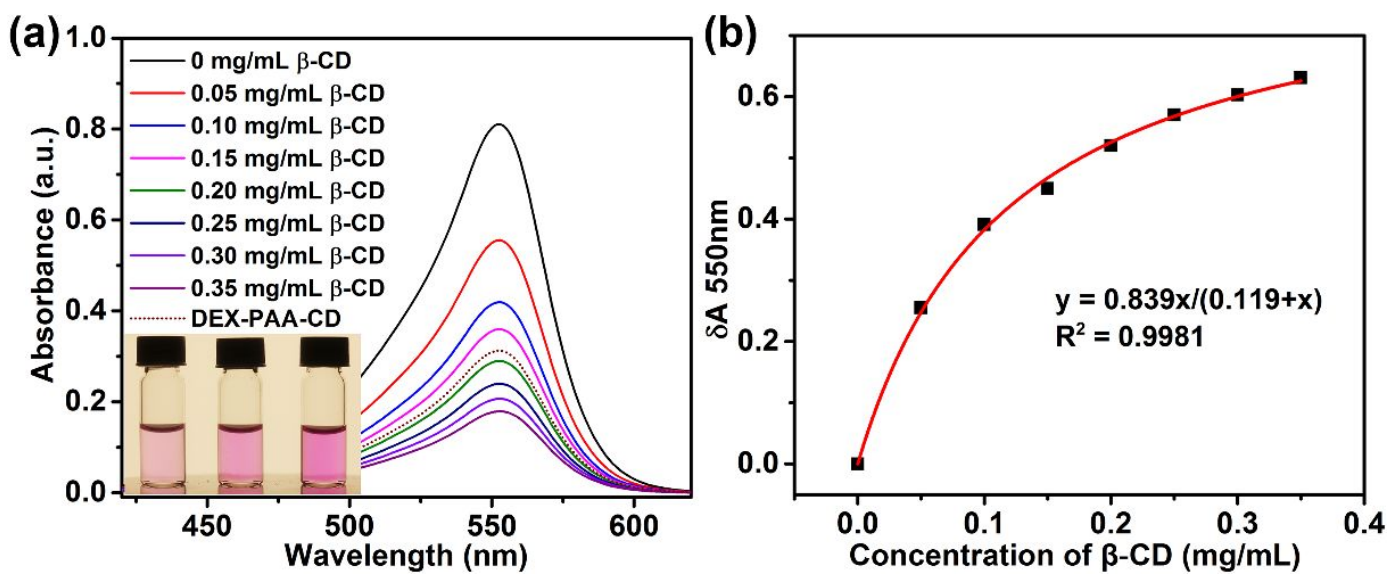

Figure S4. (a) UV-vis spectra of phenolphthalein solutions: eight containing $0-0.35$ $\mathrm{mg} / \mathrm{ml}$ of $\beta-\mathrm{CD}$ and one containing $1 \mathrm{mg} / \mathrm{mL}$ Dex-PAA-CD. Insert: Phenolphthalein solutions, containing $0.35 \mathrm{mg} / \mathrm{mL} \beta-\mathrm{CD}, 1 \mathrm{mg} / \mathrm{mL}$ Dex-PAA-CD, and no additive (from left to right). (b) Differential absorbance of phenolphtalein at $550 \mathrm{~nm}$ as a function of the concentration of $\beta-C D$. 

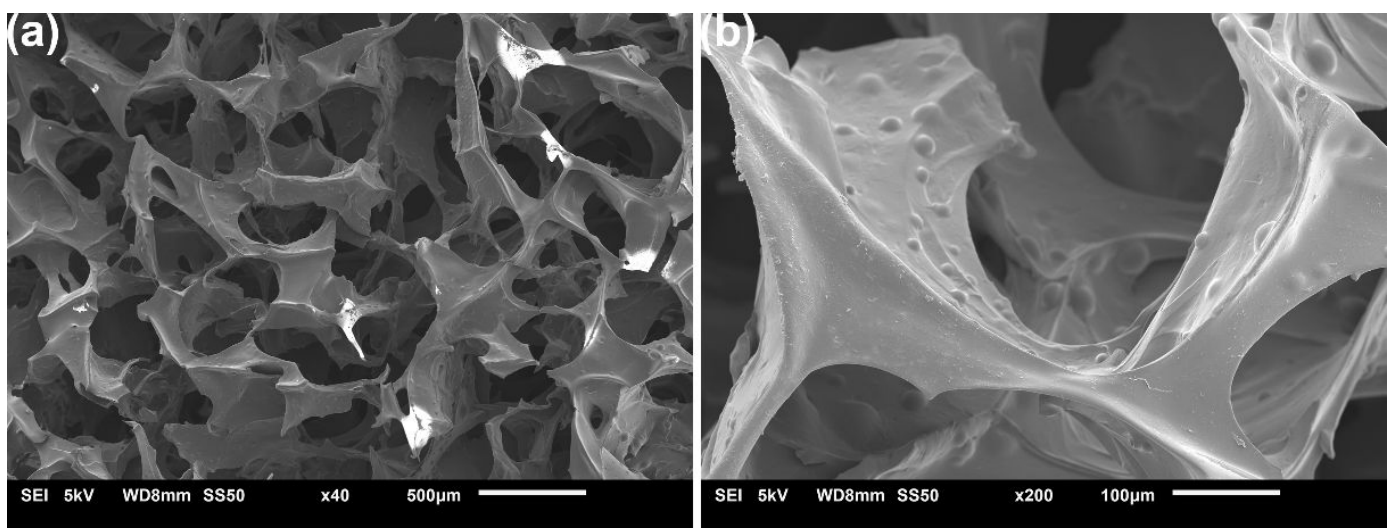

Figure S5. (a) SEM images of the freeze-dried DEX-PAA-CD hydrogel and (b) the internal structure of the pores.

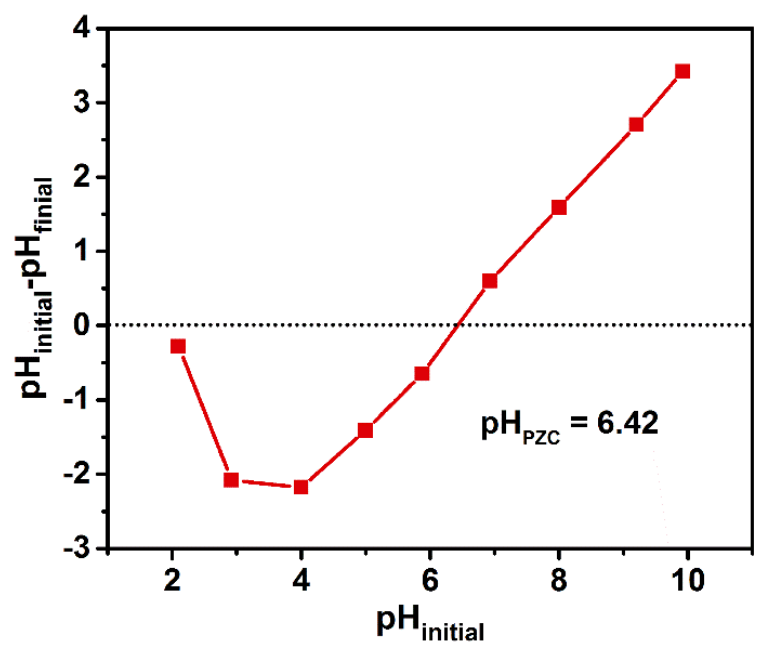

Figure S6. The difference between initial and final $\mathrm{pH}$ as a function of initial solution $\mathrm{pH}$.

(a)

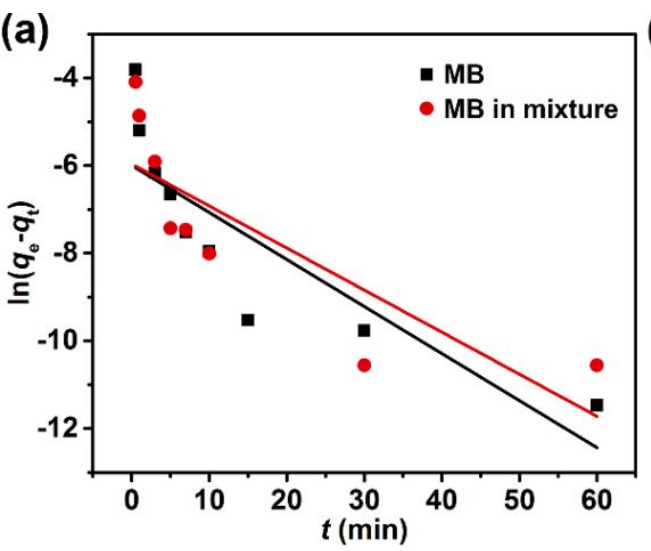

(b)

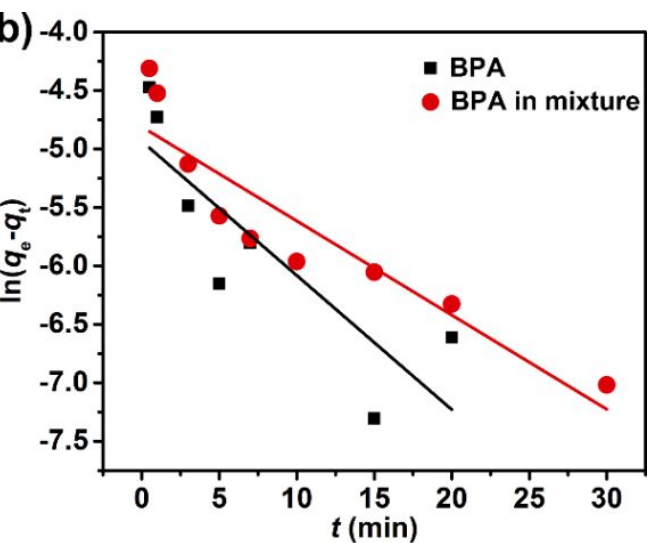


Figure S7. Pseudo-first-order kinetics of (a) MB and (b) BPA adsorption on the Dex-PAA-CD.
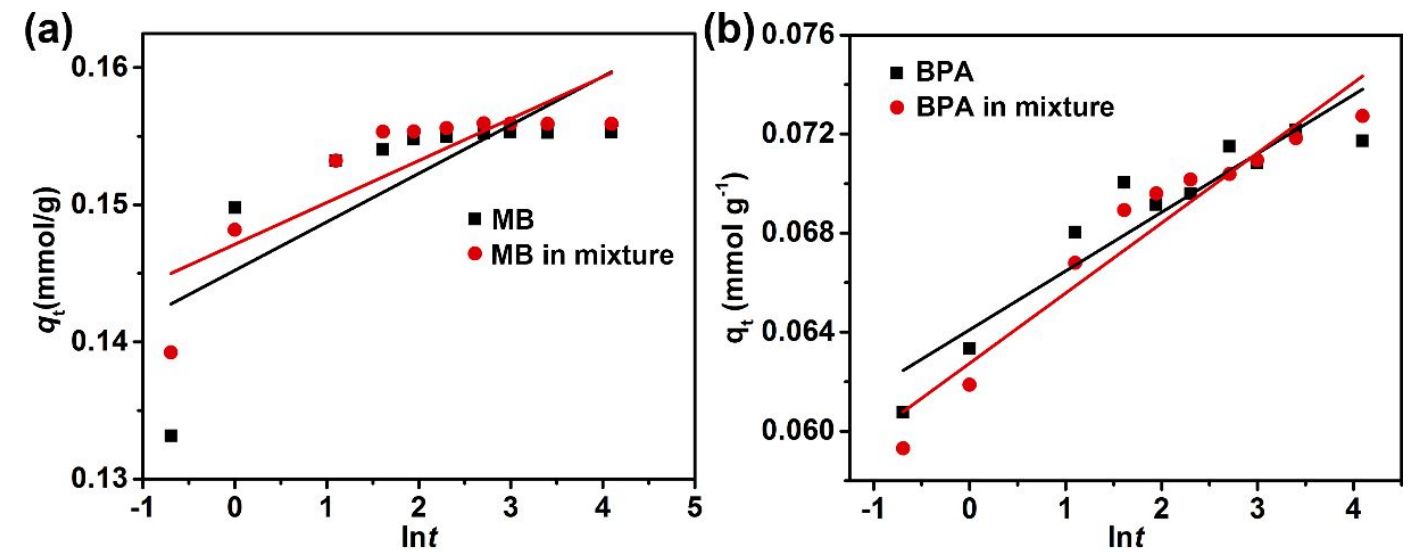

Figure S8. Elovich kinetic plots for (a) MB and (b) BPA adsorption on

Dex-PAA-CD.

Table S2. Parameters of pseudo-first order and Elovich kinetic models for MB and BPA adsorption by Dex-PAA-CD.

\begin{tabular}{cccccc}
\hline & Parameters & \multicolumn{4}{c}{ Adsorbates } \\
\cline { 3 - 6 } & & MB & MB in mixture & BPA & BPA in mixture \\
\hline Pseudo & $q_{\mathrm{e}(\mathrm{cal})}$ & 0.00249 & 0.00258 & 0.00720 & 0.00815 \\
first-order & $k_{1}$ & 0.107 & 0.096 & 0.115 & 0.0805 \\
& $R^{2}$ & 0.7013 & 0.6384 & 0.6830 & 0.8291 \\
& $\alpha$ & $2.60 \times 10^{15}$ & $2.70 \times 10^{18}$ & $1.32 \times 10^{9}$ & $1.20 \times 10^{7}$ \\
& $\beta$ & 283 & 327 & 421 & 353 \\
& $R^{2}$ & 0.5412 & 0.6727 & 0.8654 & 0.9220 \\
\hline
\end{tabular}




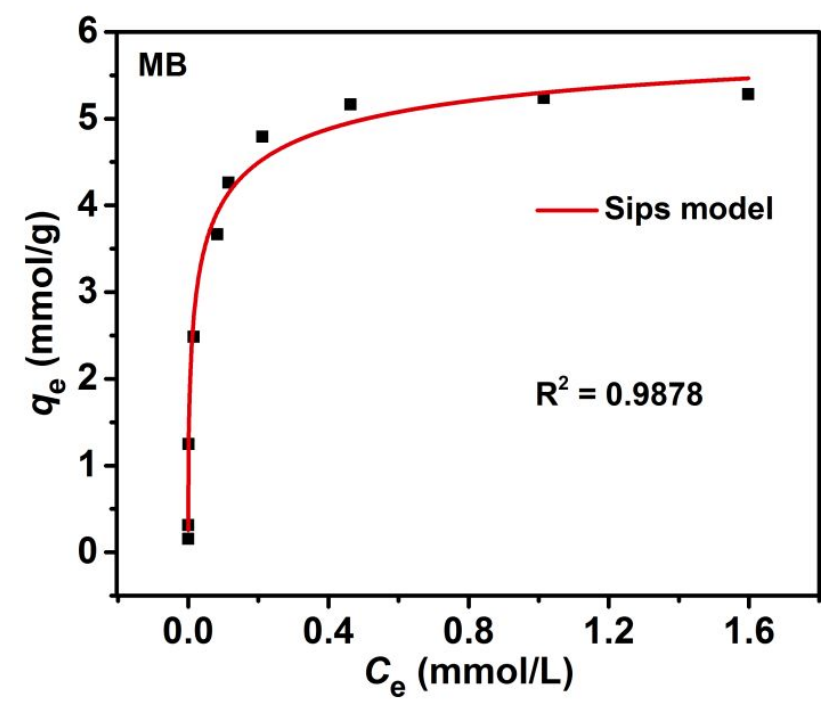

(a)

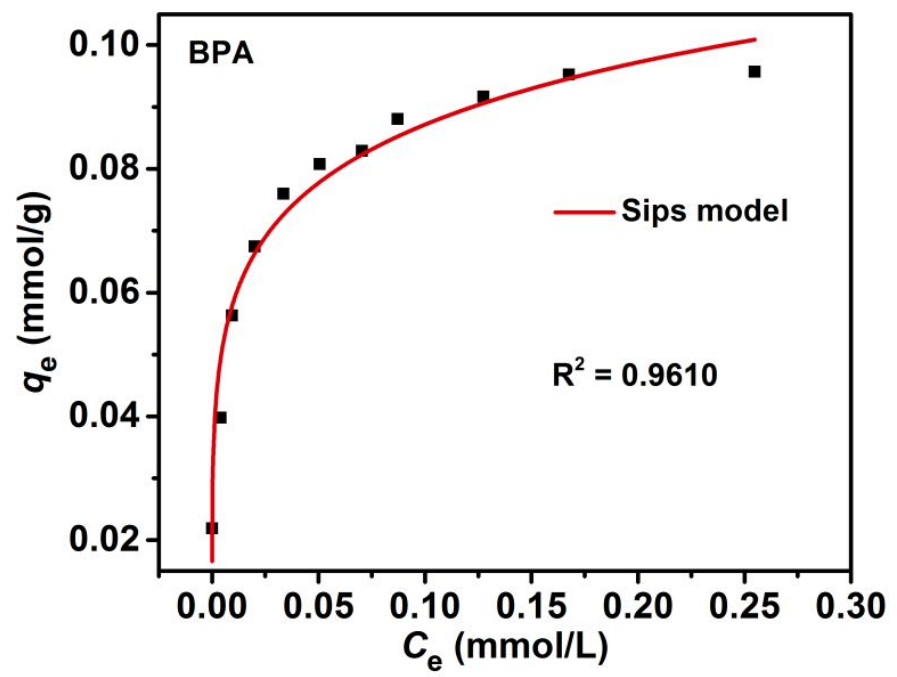

(b)

Figure S9. Sips model equilibrium plots for the adsorption of (a) MB and (b) BPA on Dex-PAA-CD at 298K. Contact time: $4 \mathrm{~h}, \mathrm{pH}_{\text {initial }}: 8.0$, the initial concentration of MB and BPA in the ranges $50-2200 \mathrm{mg} / \mathrm{L}$ and $5-80 \mathrm{mg} / \mathrm{L}$, respectively. 